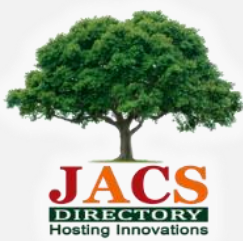

Journal of Nanoscience and Technology

\title{
Synthesis, Characterization and Efficient Photocatalytic Activity of Hydrothermally Synthesized $\mathrm{SnO}_{2}$ Nanosheets
}

\author{
V. Maria Vinosel, S. Anand, S. Pauline* \\ Department of Physics, Loyola College (Autonomous), Chennai - 600 034, Tamilnadu, India.
}

\section{ARTICLE DETAILS}

\section{Article history:}

Received 05 October 2018

Accepted 22 October 2018

Available online 28 October 2018

\section{Keywords:}

Tin Oxide

Nanosheets

Photocatalysis

Dielectric Studies

\begin{abstract}
A B S T RAC T
A systematic investigation on the preparation of $\mathrm{SnO}_{2}$ nanosheets using cost effective hydrothermal method was studied. Tetragonal phase $\mathrm{SnO}_{2}$ were synthesized using tin(II)chloride dihydarte and sodium hydroxide as precursor solution with basic water mixing. The synthesized samples were examined by XRD, HRSEM, EDAX, FTIR and UV-visible spectroscopy. The nanocrystalline size and strain of the $\mathrm{SnO}_{2}$ nanosheets have been inspected by Williamson-Hall analysis. The quantum size effect outcomes in spectacular variation in the optical and vibrational appearances of nanostructured materials likened to their bulk counterparts. Nanosheets like optical image were observed in the microscopy studies. Functional tests of $\mathrm{SnO}_{2}$ nanosheets include photocatalytic effect in the degradation of methylene blue (MB). The result revealed that $\mathrm{SnO}_{2}$ nanosheets degraded $84 \%$ of $\mathrm{MB}$ under UV light illumination. Dielectric studies such as dielectric constant, loss and ac conductivity were determined.
\end{abstract}

\section{Introduction}

Tin oxide $\left(\mathrm{SnO}_{2}\right)$ is an extensively studied $n$-type semiconductor that crystallizes in rutile tetragonal structure with a bandgap of $3.6 \mathrm{eV} \mathrm{[1].} \mathrm{TiO}_{2}$, $\mathrm{SnO}_{2}, \mathrm{SiO}_{2}, \mathrm{ZnO}$ and $\mathrm{Fe}_{2} \mathrm{O}_{3}$ are semiconductor photocatalytic materials with large bandgap. Tin oxide has several applications like gas sensors, transparent conducting electrodes, catalysts, solar cells, dye-base solar cells and rechargeable Li batteries [2]. Semiconductor nanoparticles gain further importance in research and technology for their electrifying optical properties which are significant for nano electronics, biological and catalytic applications [3]. A photocatalytic progression is built on the generation of electron-hole pairs by means of band-gap radiation that can provide rise to redox reactions with species adsorbed on surface of photocatalysts [4]. The less particle size of $\mathrm{SnO}_{2}$ nanoparticles in relationship to their excitonic Bohr radius lead into a significant difference in their optical and electronic possessions when compared to the bulk material, which can be subsequently credited to the quantum size effect. Thus small size and large specific surface area are essential for the enhanced performance of $\mathrm{SnO}_{2}$ nanoparticles and promotes the efficiency of the electron hole separation. The pollutants like organic and inorganic dyes are unconstrained into the environment from textile industries [56].Photocatalysis is most suitable method for the degradation of organic dyes into inoffensive final products. Spasiano, et al. reported that during photocatalytic reactions a reactive species are produced they are superoxide radicals and hydroxyl radicals. $\mathrm{SnO}_{2}$ nanoparticle is an essential photocatalyst applicant due to its non-toxicity, low price and chemical stability. The porous $\mathrm{SnO}_{2}$ nanowire bundles and photocatalytic influence in the degradation of $\mathrm{RhB}$ and electrochemical things as a $\mathrm{Li}$-ion battery anode was detailed by Han et al. [7]. Bhattacharjee et al. [8] reported that surfactant-mediated $\mathrm{SnO}_{2}$ NPs around 4-6 nm unveiled an efficient photocatalysis of organic waste product. A collection of methods, such as CVD, thermal evaporation, hydrothermal, sol-gel [9] are obtainable to prepare $\mathrm{SnO}_{2}$ nanosheets and nanoparticles. The hydrothermal method is most promising chemical process which is facile and cost effective. In this work, hydrothermal method was employed to synthesize $\mathrm{SnO}_{2}$ nanosheets. To emphasize the structural, photocatalytic degradation and dielectric properties of $\mathrm{SnO}_{2}$ nanosheets, standard characterizations like XRD, HRSEM, FTIR, UV and dielectric studies were examined.

\section{Experimental Methods}

\subsection{Materials}

Tin(II)chloride dihydarte $\left(\mathrm{SnCl}_{2} \cdot 2 \mathrm{H}_{2} \mathrm{O}\right)$, sodium hydroxide $(\mathrm{NaOH})$ and deionized water. All the chemicals were in analytical grade and employed as received from Merck Pvt. Ltd., without further purification.

\subsection{Method}

Surfactant free hydrothermal method was implemented to prepare $\mathrm{SnO}_{2}$ nanosheets. In a typical experiment, $4 \mathrm{~g}$ of $\mathrm{SnCl}_{2} \cdot 2 \mathrm{H}_{2} \mathrm{O}$ and $3.6 \mathrm{~g}$ of $\mathrm{NaOH}$ was dissolved in $40 \mathrm{~mL}$ of deionized water. $\mathrm{NaOH}$ solution was added to the above mixture. The homogeneous solution was obtained after stirring for $30 \mathrm{~min}$. The subsequent solution was shifted to a $100 \mathrm{~mL}$ teflon; temperature maintained for autoclave is $180^{\circ} \mathrm{C}$ for $12 \mathrm{~h}$ and then cooled naturally to room temperature. The white color precipitate formed is centrifuged and washed thoroughly with deionized water and acetone three times and dried in air at $100{ }^{\circ} \mathrm{C}$ for $12 \mathrm{~h}$ to get the final product.

\section{Results and Discussion}

\subsection{X-Ray Diffraction Analysis}

The crystalline nature of $\mathrm{SnO}_{2}$ nanosheets were determined by powder XRD analysis. Fig. 1 shows the XRD pattern of the sample. The pattern shows prominent diffraction peaks at $2 \theta$ values of $26.6^{\circ}, 33.9^{\circ}, 37.8^{\circ}, 51.9^{\circ}$ $54.8^{\circ}$ and $61.8^{\circ}$ are assigned to be (1 110$),\left(\begin{array}{lll}1 & 0 & 1\end{array}\right),\left(\begin{array}{lll}2 & 0 & 0\end{array}\right),\left(\begin{array}{lll}2 & 1 & 1\end{array}\right),\left(\begin{array}{lll}2 & 2 & 0\end{array}\right)$ and $\left(\begin{array}{lll}3 & 1 & 0\end{array}\right)$ planes respectively. The diffraction peak configurations can be indexed to the tetragonal rutile crystalline phase with lattice parameters $\mathrm{a}=4.735 \AA$ and $\mathrm{c}=3.185 \AA$ (space group: P42/mnm, JCPDS No: $41-1445$ ). This is in line with the earlier observation by Chen Yujin et al. [10]. No other peaks associated to impurities were spotted, authorizing the pure crystalline phase of $\mathrm{SnO}_{2}$ nanosheets. The broad diffraction peaks put forward the formation of $\mathrm{SnO}_{2}$ nanosheets with small crystallite size.

\subsubsection{Nelson-Riley Plot}

The lattice parameters a and $\mathrm{c}$ of $\mathrm{SnO}_{2}$ nanosheets with tetragonal structure was corrected using Nelson Riley plot. Fig. 2 and 3 shows N-R plot of lattice constant a and c. N-R curve was plotted using calculated values of lattice parameters for all the diffraction hkl planes and the error function $f(\theta)[11,12]$. 
$f(\theta)=1 / 2\left(\cos ^{2} \theta / \sin \theta+\cos ^{2} \theta / \theta\right)$

By extrapolating the error function $f(\theta)$ to zero, the corrected lattice parameter values of a and c were found to be 4.727 and 3.179 respectively.

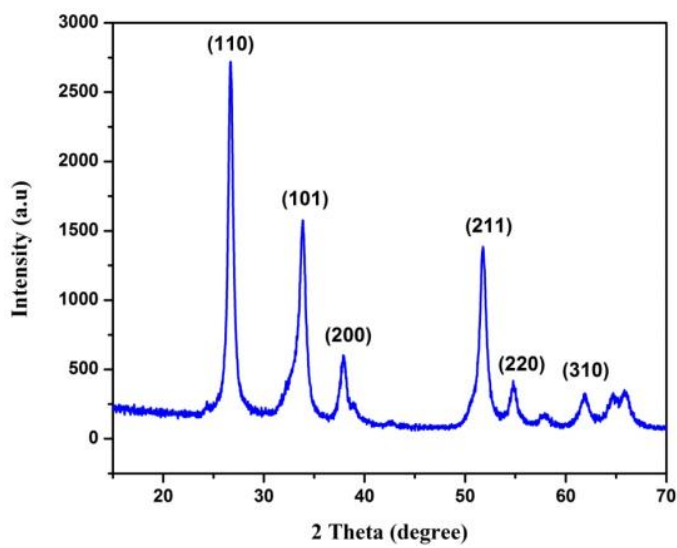

Fig. 1 XRD pattern of $\mathrm{SnO}_{2}$ nanosheets

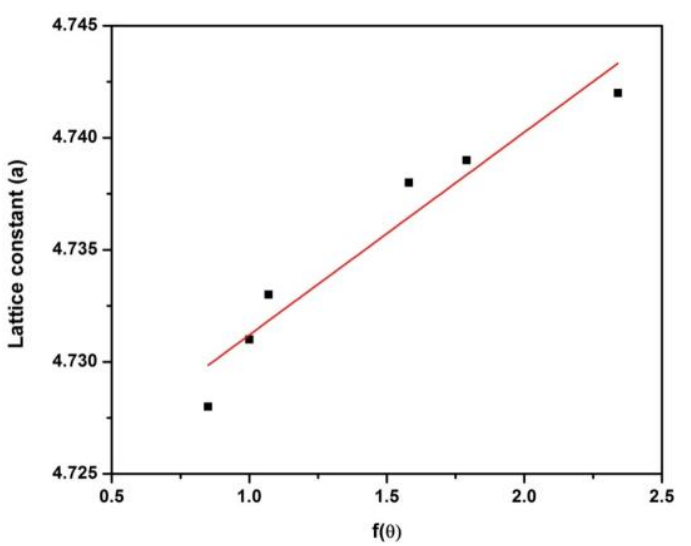

Fig. 2 Nelson Riley plot of $\mathrm{SnO}_{2}$ nanosheets for lattice constant a

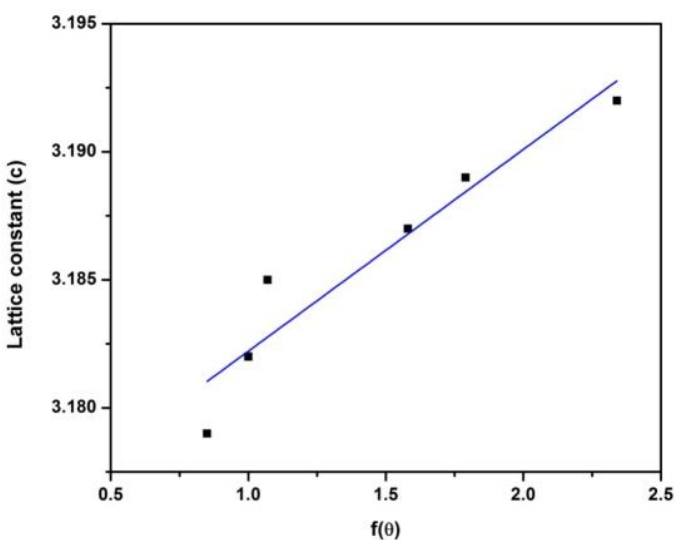

Fig. 3 Nelson Riley plot of $\mathrm{SnO}_{2}$ nanosheets for lattice constant c

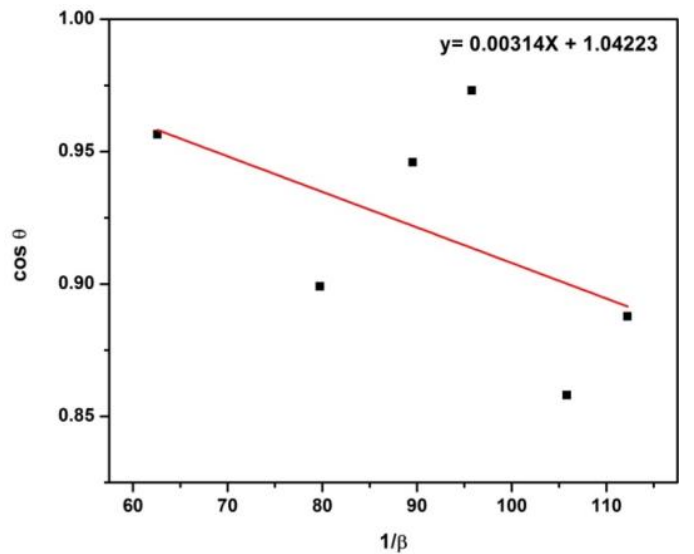

Fig.4 Scherrer plot of $\mathrm{SnO}_{2}$ nanosheets

\subsubsection{Scherrer's Method}

Lattice strain and crystallite size owing to dislocation can be estimated from peak broadening using XRD. The average crystallite size (D) has been measured by the X-ray line broadening method using Debye-Scherrer's formula, $D=K \lambda / \beta \cos \theta$, where, $D$ is average crystallite size, $K$ is shape factor (0.94), $\beta$ is full width at half maximum, $\lambda$ is $X$-ray wavelength and $\theta$ is Bragg's angle. The average size measured from Scherrer's formula was corrected using Scherrer's plots. Scherrer's plots were plotted with $1 / \beta$ and $\cos \theta$ on $\mathrm{X}$-axis and Y-axis respectively which is showed in Fig. 4. The crystallite size D was extracted from slope of the line of linear fitted data. The corrected size from Scherrer's plot is obtained as $13.89 \mathrm{~nm}$.

\subsubsection{Williamson-Hall analysis}

The $\mathrm{W}-\mathrm{H}$ analysis is an interpreted integral amplitude approach that evidently differentiates size induced and strain induced peak broadening by considering the maximum width as a function of $2 \theta$. The $\mathrm{W}-\mathrm{H}$ method does not consider $1 / \cos \theta$ dependence as in Scherrer's formula, but varies using $\tan \theta$. This fundamental alteration allows for an enlarged separation when small crystalline and micro-strain take place together. The aforementioned difference in the methodologies presented below assumes that the size and strain broadening are additive components of the overall integral width of peak $[13,14]$. The strain induced broadening rising as of imperfection and distortion of the crystal is given by,

$$
\varepsilon=\frac{\beta}{4 \tan \theta}
$$

It is confirmed that the width of the crystallite size peak varies in $1 / \cos \theta$, while strain varies in $\tan \theta$. The $\mathrm{W}-\mathrm{H}$ analysis is suitable for the calculation of the crystal size and strain. Thus, the stress-induced line that enlarges $\beta_{\mathrm{s}}$ is given by the relation,

$$
\beta s=4 \varepsilon \tan \theta ; \quad \beta h k l=\beta D+\beta s
$$

therefore, $\beta_{\mathrm{hkl}}=\frac{K \lambda}{\beta \cos \theta}+4 \varepsilon \tan \theta$

The above equation can be rearranged into

$$
\beta_{\mathrm{hkl}} \cos \theta=\frac{K \lambda}{D}+4 \varepsilon \sin \theta
$$

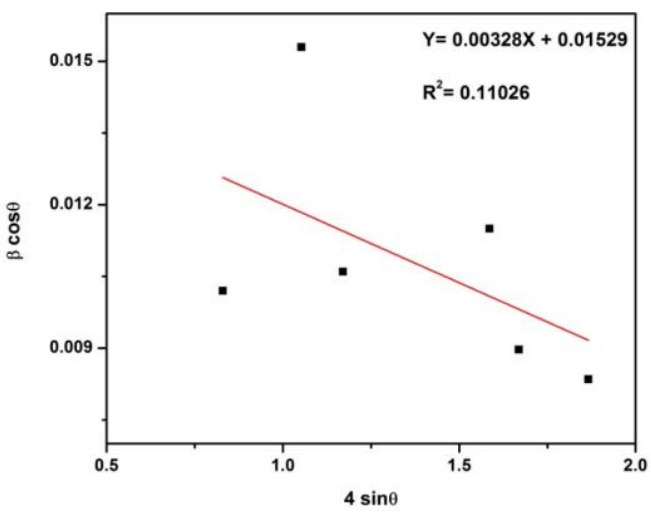

Fig. 5 Williamson-Hall plot of $\mathrm{SnO}_{2}$ nanosheets

The crystallite sizes calculated by the Williamson-Hall method vary by $9.8 \mathrm{~nm}$ even though the Scherrer's method varies by $14.4 \mathrm{~nm}$. The size of the $\mathrm{SnO}_{2}$ crystallite calculated with the Scherrer's method is considerably greater than the value found using the Williamson-Hall method. The crystallite size attained using the Scherrer's formula will be greater than the actual size due to the ignorance of the lattice strain in the Scherrer's formula. Therefore, Williamson-Hall method will provide more accurate value than Scherrer's method.

\subsection{Scanning Electron Microscopy}

The surface morphology and elemental composition of the $\mathrm{SnO}_{2}$ product were investigated using HRSEM and EDX. The morphology of the sample is depicted in Fig. 6. It is evident that $\mathrm{SnO}_{2}$ product exhibits nanosheets like morphology, which is observed to be in slight agglomeration. The sample manifests homogeneous, uniform distribution over a scanned area. Vicinisvarri Inderanal et al. [15] synthesized $\mathrm{SnO}_{2}$ nanorods by low temperature hydrothermal method which exhibited similar platelet morphology. Energy dispersive X-ray (EDX) spectra revealed the presence of stoichiometric proportion of $\mathrm{Sn}$ and $\mathrm{O}$ at weight percentage of 81.8 and 18.2 respectively without extra signals. This composition confirms the high purity of $\mathrm{SnO}_{2}$ nanosheets. 


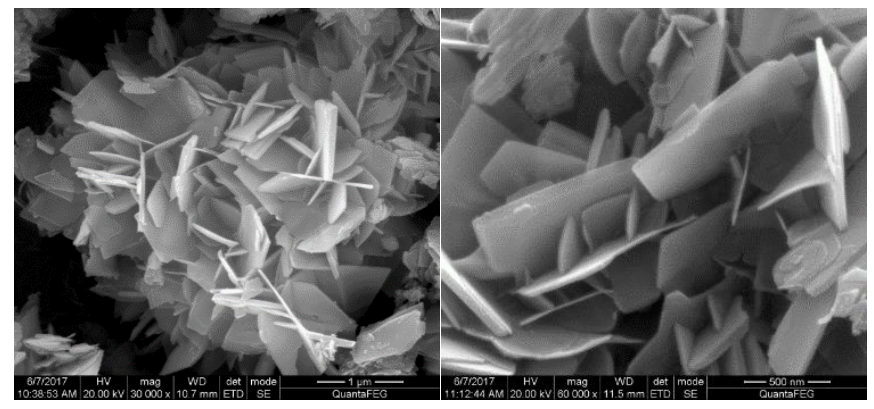

Fig. 6 HRSEM micrographs of $\mathrm{SnO}_{2}$ nanosheets

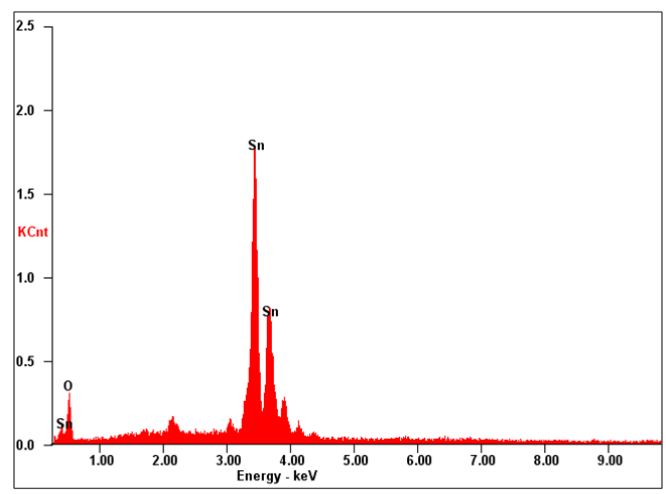

Fig. $7 \mathrm{EDX}$ analysis of $\mathrm{SnO}_{2}$ nanosheets

\subsection{Fourier Transform Infrared Spectroscopy}

Fourier transform infrared spectroscopy was chronicled to ensure the presence of functional groups of the material at room temperature. Fig. 8 shows the FTIR spectra of the prepared sample. The intense bands at 584 $\mathrm{cm}^{-1}$ were assigned to be $\mathrm{Sn}-\mathrm{O}$ metal oxygen bond. The appearance of these bands confirms the presence of $\mathrm{SnO}_{2}$ rutile phase. The strong absorption peak observed at 1632 and $3417 \mathrm{~cm}^{-1}$ can be assigned to stretching vibrations of $\mathrm{O}-\mathrm{H}$ group or the $\mathrm{O}-\mathrm{H}$ bending hydroxyl groups absorbed at the surface of $\mathrm{SnO}_{2}$ nanosheets and also to stretching vibrations of $\mathrm{Sn}-\mathrm{OH}$ groups.

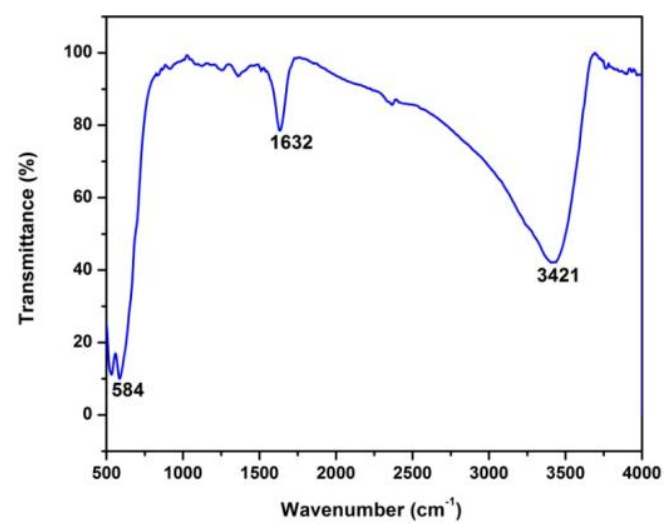

Fig. 8 FTIR spectrum of $\mathrm{SnO}_{2}$ nanosheets

\subsection{UV-Visible Spectrum Analysis}

The optical absorption band gap energy is determined using Kubelka Munk function. The absorbance spectra are shown in Fig. 9(a). The quantum confinement effect is projected for ultrafine semiconducting nanoparticles, and the absorption edge will be moved to a higher energy when the particle size decreases. The spectra exhibit a blue shift in the absorption band at $335 \mathrm{~nm}$. The optical band-gap energy ( $\mathrm{E}_{\mathrm{g}}$ ) of the semiconductor is given by an equation,

$$
(\alpha \mathrm{h} v)^{2}=\mathrm{A}\left(\mathrm{h} v-\mathrm{E}_{\mathrm{g}}\right)
$$

where, $\alpha$ is an absorption coefficient, his Planck constant, $v$ is the frequency and $h v$ is the incident photon energy [16]. Fig. 9(b) shows the Kubelka Munk plot is plotted between $(\alpha h v)^{2}$ vs hv. The direct band gap of $\mathrm{SnO}_{2}$ nanosheets was measured from the absorption coefficient as a function of wavelength using Tauc relation thereby extrapolating the linear portion to intercept on the horizontal photon energy axis and was found to $3.7 \mathrm{eV}$. Ashok et al. [17] has reported similar broadening and shift of the absorption band of $\mathrm{SnO}_{2}$ thin film by sol-gel method. The earlier reports on bulk $\mathrm{SnO}_{2}$ nanoparticle for energy band gap are $3.64 \mathrm{eV}$. The band gap is rationally greater than the bulk value which can be attributed to the quantum confinement effect.
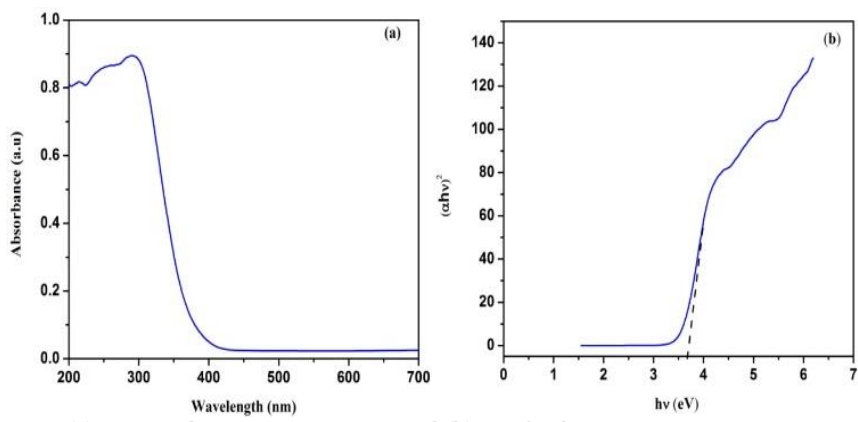

Fig. 9(a) UV-Vis absorption spectrum and (b)Tauc's plot

\subsection{Photocatalytic Activity}

\subsubsection{Mechanism of Photodegradation of Methylene Blue}

When the catalyst is illuminated with energy greater than its band gap energy, it will lead to a formation of hole $\left(\mathrm{h}^{+}\right)$in the valence band and an electron (e) in the conduction band of $\mathrm{SnO}_{2}$ product. The hole $\left(\mathrm{h}^{+}\right)$acts as an oxidizing agent and oxidizes the pollutant directly or water to form hydroxyl radicals. The electron ( $\mathrm{e}$ ) in the conduction band acts a reducing agent and reduces the oxygen adsorbed on the $\mathrm{SnO}_{2}$ nanocatalyst. The excited dye injects an electron to the conduction band of $\mathrm{SnO}_{2}$ photocatalyst, which it is scavenged by preadsorbed oxygen, $\mathrm{O}_{2}$ to form active oxygen radicals. Theses active radicals drive the photodegradation process.

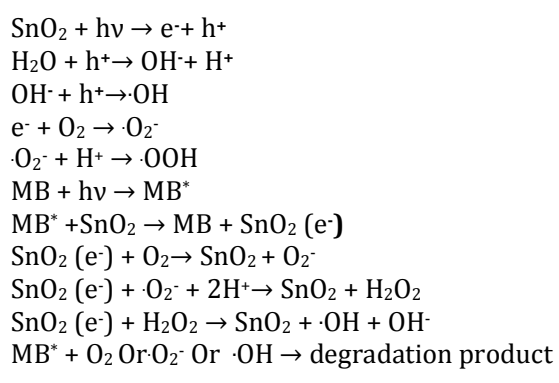

The photocatalytic activity of the synthesized $\mathrm{SnO}_{2}$ nanosheets was examined by monitoring the changes in the optical absorption spectra of methylene blue (MB) solution during its photocatalytic degradation process. To optimize the photocatalytic degradation time, the experiment was carried out at different time interval. Fig. 10(a) shows the UV-visible spectra for the photocatalytic degradation of MB dye using $\mathrm{SnO}_{2}$ nanosheets for different time intervals. The absorption bands positioned for methylene blue at $\lambda=290 \mathrm{~nm}$ and $\lambda=664 \mathrm{~nm}$ steadily decreases with increasing irradiation time. The intensity of the maximum adsorption peak at $664 \mathrm{~nm}$ decreased monotonously as the illumination time increases, which indicates the degradation of the MB dye. Fig. 10(b) shows the kinetic fit for the degradation of methylene blue between $\mathrm{C}_{\mathrm{t}} / \mathrm{C}_{\mathrm{o}}$ versus irradiation time. $\mathrm{C}_{0}$ and $\mathrm{C}_{\mathrm{t}}$ are the initial dye concentration and the concentration at reaction time $\mathrm{t}$ respectively. These results revealed that $\mathrm{SnO}_{2}$ nanosheets exhibit $84 \%$ of efficiency in the degradation of methylene blue dye after 180 min under UV light illumination. The nanocatalyst which exhibits good catalytic activity has several factors such as small crystallite size, bandgap value and large surface area.
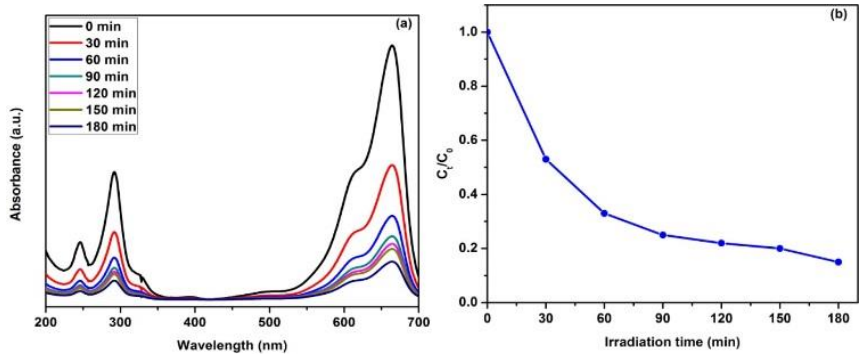

Fig. 10 (a) time-dependent UV-vis absorption spectra and (b) plot of $C_{t} / C_{0}$ vs irradiation time for photodegradation of methylene blue 


\subsection{Dielectric Studies}

The dielectric constant $\left(\varepsilon^{\prime \prime}\right)$ contains dielectric constant of the test material and dielectric loss. The dielectric constant $\left(\varepsilon^{\prime}\right)$ can be obtained using the following relation:

$$
\varepsilon^{\prime}=\frac{t \times C p}{A \times \varepsilon_{o}}
$$

where, $\mathrm{t}$ is thickness, $\mathrm{C}_{\mathrm{p}}$ is capacitance, $\varepsilon_{\mathrm{o}}$ is permittivity of the free space $\left(8.85 \times 10^{-12} \mathrm{~F} / \mathrm{m}\right)$ and $\mathrm{A}$ is the sample area. The dielectric constant with regard to the frequency for the $\mathrm{SnO}_{2}$ nanosheets is shown in Fig. 11 and it is evident that it decreases with the increase of the applied frequency due to the polarization mechanism with the applied frequency [14-17]. In the middle frequency region of $1 \mathrm{kHz}$ and $1 \mathrm{MHz}$, the total contribution of the polarization derives from the electronic, ionic, displacements of the space charge and from the orientation of the dipole.

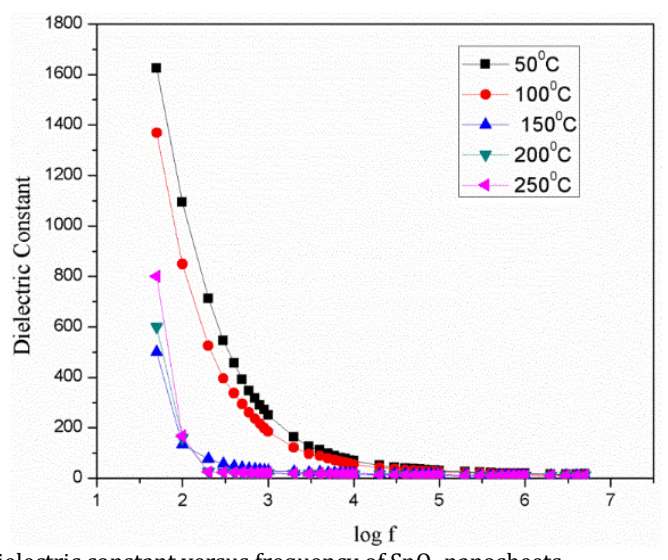

Fig. 11 Dielectric constant versus frequency of $\mathrm{SnO}_{2}$ nanosheets

The dielectric loss $\left(\varepsilon^{\prime \prime}\right)$ compared to the applied frequency is given in Fig. 12 and decreases with increasing frequency, which demonstrates the ability of these materials to be used in high frequency applications. Loss is found to be average frequency region during 50 and $100{ }^{\circ} \mathrm{C}$, which is the result of the dipole polarization. This polarization relies on the atomic, interfacial and electronic polarizations which are due to the electronic polarization at higher frequencies [18-21]. The contribution of the polarization of the space charge due to the free spaces of the oxygen ions increases the dielectric loss at all temperatures.

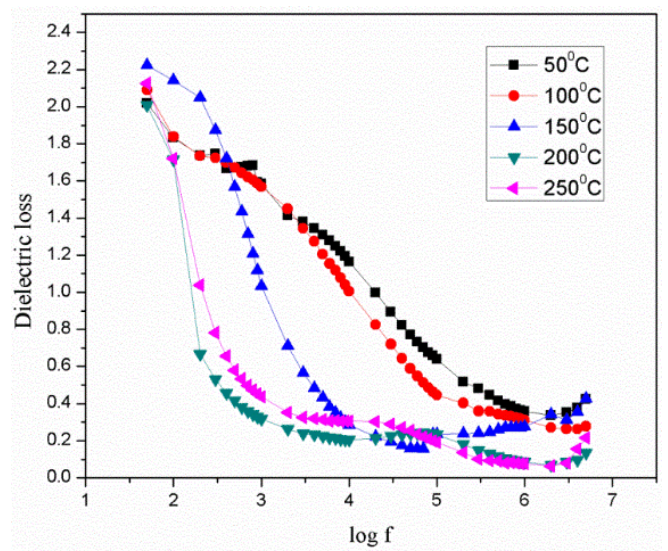

Fig. 12 Dielectric loss versus frequency of $\mathrm{SnO}_{2}$ nanosheets

The AC conductivity ( $\sigma_{\mathrm{ac}}$ ) of the nanosheets of $\mathrm{SnO}_{2}$ is calculated using the following relation, the frequency-dependent $\mathrm{AC}$ conductivity could be described by the Jonscher's universal power law and its variation with the applied frequency is shown in Fig. 13.

$$
\sigma_{a c}=\omega \varepsilon_{o} \varepsilon^{\prime} \tan \delta
$$

where $\sigma_{\mathrm{ac}}$ is permittivity of free space and $\omega$ is angular frequency. AC conductivity increased with increasing applied frequency for all the temperatures. At low frequency, the particles have DC and high frequency conductivity, so they have $\mathrm{AC}$ conductivity. In general, electrical conductivity is straightly correlated to the obtainable quantity of free charge carriers and their mobility. AC conductivity is influenced by mobile charge operators. According to an ion-hopping mechanism, the ion conduction of the $\mathrm{SnO}_{2}$ sample derives from the migration of https://doi.org/10.30799/jnst.163.18040513 interchangeable channels and grain cavities. While the movable load carriers rise to a new position, from their original position, they face a certain shift between the two states of minimum potential energy. This is owing to the polarization of the dipoles, i.e. the dipoles rotate between the equivalent equilibrium positions.

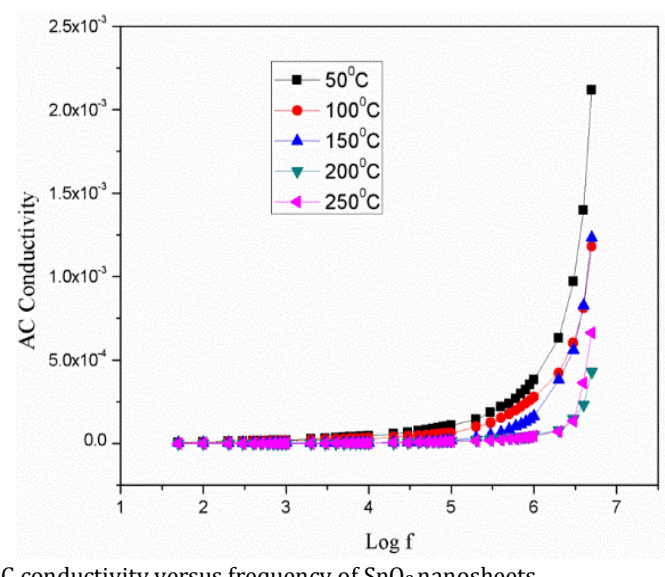

Fig. $13 \mathrm{AC}$ conductivity versus frequency of $\mathrm{SnO}_{2}$ nanosheets

\section{Conclusion}

In summary, hydrothermal method was successfully demonstrated to prepare $\mathrm{SnO}_{2}$ nanosheets. The rutile tetragonal structure of $\mathrm{SnO}_{2}$ was confirmed by the X-ray diffraction. SEM analysis of $\mathrm{SnO}_{2}$ product was observed to be nanosheets with homogeneous in size distribution. EDX pattern endorses the existence of tin and oxygen elements respectively. The FTIR spectrum of $\mathrm{SnO}_{2}$ nanosheets with strong absorption peaks at $637 \mathrm{~cm}^{-1}$ is assigned for Sn-O metal oxygen bond and the peak observed at $3417 \mathrm{~cm}^{-1}$ confirms the presence of $\mathrm{O}-\mathrm{H}$ groups. The absorption peak of the sample indicates it has absorption up to $335 \mathrm{~nm}$ after that there appears wide transparency window and the absence of absorption in optical region. The photodegradation efficiency of $\mathrm{SnO}_{2}$ nanosheets with MB dye under UV illumination is $84 \%$. It is envisaged that prepared $\mathrm{SnO}_{2}$ nanosheets are useful photocatalyst which exhibited good catalytic activity.

\section{References}

[1] M. Meena Kumari, Daizy Philip, Synthesis of biogenic $\mathrm{SnO}_{2}$ nanoparticles and evaluation of thermal, rheological, antibacterial and antioxidant activities, Powder Technol. 270 (2015) 312-319.

[2] V.K. Vidhu, Daizy Philip, Phytosynthesis and applications of bioactive $\mathrm{SnO}_{2}$ nanoparticles, Mater. Charact. 101 (2015) 97-105.

[3] E. Lam, S. Hrapovic, E. Majid, J.H. Chong, J.H.T. Luong, Catalysis using gold nanoparticles decorated on nanocrystalline cellulose, Nanoscale 4(3) (2012) 997-1002.

[4] C. Wang, BQ Xu, X. Wang, J. Zhao, Preparation and photocatalytic activity of $\mathrm{ZnO} / \mathrm{TiO}_{2} / \mathrm{SnO}_{2}$ mixture, J. Solid State Chem. 178 (2005) 3500-3506.

[5] G. Elango, S.M. Roopan, Efficacy of $\mathrm{SnO}_{2}$ nanoparticles toward photocatalytic degradation of methylene blue dye, J. Photochem. Photobio. B: Bio. 155 (2016) 34-38.

[6] S. Skariyachan, A. Prasanna, S.P. Manjunath, S.S. Karanth, A. Nazre, Environmental assessment of the degradation potential of mushroom fruit bodies of Pleurotus ostreatus (Jacq.: Fr.) P. Kumm. Towards synthetic azo dyes and contaminating effluents collected from textile industries in Karnataka, India, Environ. Monit. Assess. 188(121) (2016) 1-8.

[7] D. Spasiano, R. Marotta, S. Malato, P. Fernandez-Ibanez, I. Somma, Solar photocatalysis: materials, reactors, some commercial, and pre-industrialized applications. A comprehensive approach, Appl. Catal. B: Environ. 170-171 (2015) 90-123.

[8] Yutao Han, Xiang Wu, Yulin Ma, Lihong Gong, Fengyu Qu and Hongjin Fan, Porous $\mathrm{SnO}_{2}$ nanowire bundles for photocatalyst and $\mathrm{Li}$ ion battery applications, Cryst. Eng. Comm. 13 (2011) 3506-3510.

[9] D. Davazoglou, Optical properties of $\mathrm{SnO}_{2}$ thin films grown by atmospheric pressure chemical vapour deposition oxiding $\mathrm{SnCl}_{4}$, Thin Solid Films 302 (1997) 204-213.

[10] Chen YuJin, Zhu Chun Ling, Wang Li Jiao, Wang Tai Hong, One-pot synthesis of crystalline $\mathrm{SnO}_{2}$ nanoparticles and their low-temperature ethanol sensing characteristics, Science in China Series G: Phys.: Mech. Astron. 52(10) (2009) 1601-1605.

[11] J.B. Nelson, D.P. Riley, An experimental investigation of extrapolation methods in the derivation of accurate unit-cell dimensions of crystals, Proc. Phys. Soc. London 57 (1975) 160-177.

[12] A. Persis Amaliya, S. Anand, S. Pauline, Investigation on structural, electrical and magnetic properties of titanium substituted cobalt ferrite nanocrystallites, J. Magn. Magn. Mater. 467 (2018) 14-28. 
[13] S. Anand, A. Persis Amaliya, M. Asisi Janifer, S. Pauline, Structural, morphological and dielectric studies of zirconium substituted $\mathrm{CoFe}_{2} \mathrm{O}_{4}$ nanoparticles, Mod. Electron. Mater. 3 (2018) 168-173.

[14] M. Asisi Janifer, S. Anand, M. Senthuuran, S. Pauline, Effect of synthesis conditions on yttrium iron garnet (YIG) nanocrystalline powder via sol gel method, Int. Res. J. Eng. Technol. 04(09) (2017) 78-81.

[15] Vicinisvarri Inderan, Shin Ye Lim, Teng Sian Ong, Samuel Bastien, Nadi Braidy, Hooi Ling Lee, Synthesis and characterisations of $\mathrm{SnO}_{2}$ nanorods via low temperature hydrothermal method, Superlatt. Microstr. 88 (2015) 396-402.

[16] V. Maria Vinosel, M. Asisi Janifer, S. Anand, S. Pauline, Structural and functional group characterization of nanocomposite $\mathrm{Fe}_{3} \mathrm{O}_{4} / \mathrm{TiO}_{2}$ and its magnetic property, Mater. Sci. Eng. 9 (2017) 160-166.

[17] A.D. Bhagwat, S.S. Sawant, B.G. Ankamwar, C.M. Mahajan, Synthesis of nanostructured tin oxide $\left(\mathrm{SnO}_{2}\right)$ powders and thin films prepared by sol-gel method, J. Nano Elect. Phys. 7(4) (2015) 04037-1-4.
[18] M. Maria Lumina Sonia, S. Anand, V. Maria Vinosel, M. Asisi Janifer, S. Pauline, A. Manikandan, Effect of lattice strain on structure, morphology and magnetodielectric properties of spinel $\mathrm{NiGd}_{x} \mathrm{Fe}_{2-\mathrm{x}} \mathrm{O}_{4}$ ferrite nano-crystallites synthesized by sol-gel route, J. Magn. Magn. Mater. 466 (2018) 238-251.

[19] M. Maria Lumina Sonia, S. Anand, V. Maria Vinosel, M. Asisi Janifer, S. Pauline, Effect of lattice strain on structural, magnetic and dielectric properties of solgel synthesized nanocrystalline $\mathrm{Ce}^{3+}$ substituted nickel ferrite, J. Mater. Sci. Mater. Electron. 29(17) (2018) 15006-15021.

[20] A. Persis Amaliya, S. Anand, S. Pauline, CTAB assisted synthesis of cobalt ferrite nanoparticles and its characterizations, J. Nanosci. Technol. 2 (2016) 186-188.

[21] M. Maria Lumina Sonia, S. Anand, S. Blessi, S. Pauline, A. Manikandan, Effect of surfactants (PVB/EDTA/CTAB) assisted sol-gel synthesis, structural, magnetic and dielectric properties of $\mathrm{NiFe}_{2} \mathrm{O}_{4}$ nanoparticles, J. Ceram. Int. (2018) Accepted Manuscript. DOI: 10.1016/j.ceramint.2018.08.317. 